\title{
Smart Electric Mobility Operating System Integrated with Off-Grid Solar Power Plants in Tanzania: Vision and Trial Run
}

\author{
Hyop-Seung Rhee ${ }^{1}$, Hyuck-Soon $\mathrm{Im}^{2}$, Frank Andrew Manongi ${ }^{2}$, Young-In Shin ${ }^{3}$, \\ Ho-Won Song ${ }^{3}$, Woo-Kyun Jung ${ }^{4}$, Sung-Hoon Ahn ${ }^{2,3, \dagger}$ \\ ${ }^{1}$ Innovative Technology and Energy Center(iTEC), P.O Box 846, Arusha, Tanzania \\ ${ }^{2}$ Department of Mechanical Engineering, Seoul National University, 1 Gwanak-ro, Gwanak-gu, Seoul 08826, Republic of Korea \\ ${ }^{3}$ Institute of Advanced Machines and Design, Seoul National University, 1 Gwanak-ro, Gwanak-gu, Seoul 08826, Republic of Korea \\ ${ }^{4}$ Soft Robotics Research Center, 1 Gwanak-ro, Gwanak-gu, Seoul 08826, Republic of Korea
}

\section{탄자니아의 태양광 발전소와 통합된 전기 모빌리티 운영 시스템 : 비전과 시범운행}

\author{
이협승 ${ }^{1}$, 임혁순 ${ }^{2}$, 프랭크 앤드류 마농기 ${ }^{2}$, 신영인 $^{3}$, 송호원 $^{3}$, 정우균 ${ }^{4}$, 안성훈 ${ }^{2,3, \uparrow}$ \\ 1한국-탄자니아 에너지-산업연계 적정기술거점센터(iTEC), P.O box 846, 아루샤, 탄자니아 \\ ${ }^{2}$ 서울대학교 기계공학부, 서울시 관악구 관악로 1 , 대한민국 \\ ${ }^{3}$ 서울대학교 정밀기계설계공동연구소, 서울시 관악구 관악로 1 , 대한민국 \\ ${ }^{4}$ 인간중심소프트로봇기술연구센터, 서울시 관악구 관악로 1 , 대한민국
}

\begin{abstract}
전 세계적인 지구온난화의 위협에 대응하고자 세계 각국은 신재생 에너지의 확산, 탄소 배출 감소 등을 추진하고 있 다. 또한, $\mathrm{UN}$ 의 SDGs에도 포함된 기후변화에 맞서기 위한 노력으로 글로벌 자동차 제조사들은 향후 10 년내에 전기 자동차로의 전면 전환을 추진하고 있다. 전기자동차는 탄소 배출 감소를 위한 유용한 수단이 될 수 있으나, 충전용 전 기를 생산하는 단계에서 발생하는 탄소의 저감을 위해서는 친환경 신재생 에너지를 이용한 발전시스템이 요구된다. 본 연구에서는 아프리카 탄자니아에 설립된 태양광 발전소와 통합된 스마트 전기 모빌리티 운영 시스템에 대한 비전을 제 안한다. 아두이노 컴퓨팅 장치를 기반으로 하는 스마트 모니터링 및 통신 기능을 적용하여 전기자동차 또는 전기 오 토바이의 배터리 잔존용량, 배터리 상태, 위치, 속도, 고도, 도로 상태 등의 정보를 모니터링한다. 또한, 주변의 독립형 태양광 발전소 인프라와 통신하여 주행가능거리를 예측하고 충전 스케쥴 및 목적지까지의 경로 최적화를 수행하는 시 나리오를 제시한다. 제안된 시스템의 구현 가능성은 전기 오토바이의 시험운행을 통해 검증되었다. 탄자니아에서 운 영될 전기 모빌리티 시스템은 현지의 환경과 특성을 고려하여 친환경성, 경제성, 운용 용이성, 호환성 등의 요소가 고 려되어야 한다. 본 연구에서 제안하는 스마트 전기 모빌리티 운영 시스템은 SDGs의 이행을 위한 중요한 기반이 될 수 있을 것이다.
\end{abstract}

To respond to the threat of global warming, countries around the world are promoting the spread of renewable energy and reduction of carbon emissions. In accordance with the United Nation's Sustainable Development Goal to combat climate change and its impacts, global automakers are pushing for a full transition to electric vehicles within the next 10 years. Electric vehicles can be a useful means for reducing carbon emissions, but in order to reduce carbon generated in the stage of producing electricity for charging, a power generation system using eco-friendly renewable energy is required. In this study, we propose a smart electric mobility operating system integrated with off-grid solar power plants established in Tanzania, Africa. By applying smart monitoring and communication functions based on Arduino-based computing devices, information such as remaining battery capacity, battery status, location, speed, altitude, and road conditions of an electric vehicle or electric motorcycle is monitored. In addition, we present a scenario that communicates with the surrounding independent solar power plant infrastructure to predict

†To whom correspondence should be addressed.

E-mail: ahnsh@snu.ac.kr

Received: 30 September 2021, Revised : 18 October 2021

Accepted: 18 October 2021 the drivable distance and optimize the charging schedule and route to the destination. The feasibility of the proposed system was verified through test runs of electric motorcycles. In considering local environmental characteristics in Tanzania for the operation of the 
electric mobility system, factors such as eco-friendliness, economic feasibility, ease of operation, and compatibility should be weighed. The smart electric mobility operating system proposed in this study can be an important basis for implementing the SDGs' climate change response.

KEYWORDS: Sustainability, Electric mobility, Off-grid power plant, Charging schedule optimization

서론

전 세계는 최근 급격한 지구 온난화에서 기인된 폭우와 홍수 등의 기상 이변으로 많은 어려움을 겪고 있다(World Meterological Organization, 2020). 이에 대한 대응 방안에 대 해서는 2015년 채택된 UN SDGs(Sustainable Development Goals)에서도 다양하게 제시되고 있는데, G7(Affordable and Clean Energy : 적정한 가격에 신뢰할 수 있고 지속 가능한 에너지에 대한 접근 보장), G11(Sustainable Cities and Communities : 포용적이고 안전하며 지속가능한 도시와 주 거지), G12(Responsible Consumption and Production : 지속 가능한 소비와 생산의 보장), G13(Climate Action : 기후 변 화와 그로 인한 영향에 맞서기 위한 대응) 등이 이러한 기 후변화와 이에 대한 인류 공동의 목표로 명시되었다.

지구온난화 등 기후 변화에 대한 구체적인 대안으로는 글 로벌 탄소 중립 추진, 신재생 에너지의 확산 등이 제시되고 있는데, 탄소 배출 '제로화’를 위한 소요 기술, 리더십 등의 전략적 도구 등에 대한 제안(Schreyer et al., 2020), 탄소배 출량과 에너지 사용량, 탄소세의 연관성을 통해 탄소 배출 을 감소시킬 수 있는 요인에 대한 연구(Garidzirai, 2020) 등 이 진행되고 있다. 또한, 신재생 에너지 $100 \%$ 추진을 위한 스마트 에너지 도시 구성에 대한 제안(Thellufsen et al., 2020) 등과 함께 신재생 에너지에 대한 정책 지원도 계속될 예정이다(International Energy Agency, 2020).

최근 제너럴모터스 $(\mathrm{GM})$, 볼보, 포드 등의 글로벌 자동차 제조사들은 향후 10 년을 전후하여 기존의 내연기관을 탈피 하고 전기차로 완전히 전환하는 계획을 발표하고 있다. 이 러한 추세는 단순한 차량 제조업계의 트렌드가 아니라 인 류의 지속가능성을 확보하고자 하는 중요하고 엄중한 노력 이라고 할 수 있다. 하지만, 전기차로의 전환은 전기차 자 체 요소 기술의 개발과 함께, 충전 인프라의 구축이 병행되 어야 한다. 이를 위한 예산과 시간의 문제는 세계 여러 나 라에서 국가적 문제로 인식하고 이를 해결하기 위해 다양 한 노력을 기울이고 있다. 그러나, 에너지 기반시설 자체가 부족한 많은 개발도상국에게는 이러한 범세계적 추세에 부 응하는 것은 현실적으로 불가능하다고 할 수 있다.

아프리카 등 개발도상국에서는 태양광, 풍력 등 재생 에
너지를 이용한 전력 확보에 많은 노력이 시도되고 있는데 (Khan et al., 2018; Bokopane et al., 2014), 본 연구에서는 전 기차에 대한 충전 인프라 및 운용과 관련된 최근 연구동향 을 살펴보고, 아프리카의 대표적 개발도상국인 탄자니아의 전기차 운영 환경 및 요구사항을 분석하고, 기존에 건설된 태양광 발전소와 통합하여 탄자니아에 적용 가능한 전기 모 빌리티 운영 시스템을 제안하고자 한다.

\section{전기차 충전 인프라 및 운용 관련 연구 동향}

전 세계적으로 다양한 전기차가 상용화되어 운용되고 있 지만, 전기차 생산업체들은 내연기관 자동차의 $100 \%$ 전기 차 전환을 위해서는 충전 인프라, 배터리 가용성, 경제성과 함께 전기차의 필요에 대한 소비자 공감을 유도하는 것이 반드시 필요하다고 인식하고 있다. 특히, 충전 인프라에 대 한 중요성은 가장 큰 문제로 제기되고 있는데, 전기 보급률 이 높지 않은 아프리카와 같은 저개발 국가에서는 충전 인 프라가 전기차 시스템의 운용에 있어서 가장 큰 장애물이 될 수 있다(Rajper and Albrecht, 2020).

전기차 충전 인프라의 구축 및 운용에 대한 연구는 다양 하게 수행되고 있는데, 다수의 충전 소스를 기반으로 전기 차 충전소의 충전 효율을 검토한 연구(Erick and Folly, 2020), 전기차 충전소의 충전 시스템에 대한 실시간 모니터 링 및 충전 슬롯의 가용성을 예측한 연구(Chokkalingam $e t$ $a l .$, 2017), 메타 휴리스틱 접근 방법을 통해 전기차 충전 스 케쥴을 최적화 하는 방법에 대한 연구(Yang et al., 2014), 전 기차 충전 시스템에 대한 충전 및 방전 관리 제어 알고리 즘에 대한 연구(Nguyen et al., 2014) 등이 수행되어 왔다.

한편, 신재생 에너지를 이용한 전기차의 충전 시스템에 대 한 연구도 다양하게 수행되고 있는데, Fathabadi (2017)는 태 양열 기반의 전기차 충전 시스템을 구축하고 이를 기반으 로 기상에 따른 충전 가능성을 분석하였으며, Bimenyimana et al. (2021)은 르완다에서 태양광 발전 마이크로그리드를 전기차 충전에 연결하는 방안에 대하여 제안하였다. 또한, 저용량 독립형 태양광 발전기를 이용한 충전 모델의 개발 이 시도되기도 하였다(Mueller and Mueller, 2014).

부가하여, 충전 시스템 및 교통 흐름과 연계한 전기차의 
에너지 관리 전략에 대한 연구(Sun et al., 2015), 전기차 통 합 전력관리 최적화 프레임워크 개발(Hu et al., 2015) 등과 함께, 배터리와 전기 모터 등 전기차의 주요 부품에 대한 신 뢰성과 안전성에 대한 연구(Gandoman et al., 2019), 전기차 의 시간에 따른 에이징 파라미터와 구동 횟수에 따른 사이 클링 파라미터를 통합적으로 관리하여 비용 모델을 산출한 연구(Ahmadian et al., 2018) 등 전기차의 운용과 관련된 다 양한 연구가 수행되고 있다.

\section{탄자니아에서의 전기 모빌리티 운영 환경 및 요구사항 분석}

\section{1. 운영 환경 분석}

탄자니아(United Republic of Tanzania, 탄자니아 연합공화 국)는 적도 아래 아프리카 동남부 인도양 연안에 위치하여 케냐, 우간다, 르완다, 모잠비크, 잠비아 등 8 개국과 국경을 맞대고 있는 동아프리카에서 가장 큰 면적의 국가이다. 탄 자니아 정부는 탄자니아 개발 비전 2025를 통해 생활수준 의 질적 향상과 지속가능한 성장을 도모하고 있는데(The united republic of Tanzania. planning commission, 1999), 특 히 '전력 공급 산업 개혁 로드맵'을 통해 탄자니아 전역에 전력 연결망 설치를 목표로 하고 있다. 지속 가능한 사회 및 경제적 변환과 환경을 고려하여 도시 및 교외 지역 전력 공 급망을 2033년까지 $75 \%$ 수준으로 달성하는 것을 목표로 하 고 있다(The united republic of Tanzania. Ministry of energy and minerals, 2015).

탄자니아의 발전이 지속되고 있음에도 불구하고 넓은 국 토 면적과 인구의 분산은 낮은 전력 보급률의 원인이 되고 있다. 현재 전 국토의 약 $32.8 \%$ 만이 전력을 공급받고 있는 데, 교외 지역은 약 $7 \%$ 수준에 불과한 실정이다. 또한 천연 가스와 수력발전에 대한 의존도가 높은 상황으로 견고한 인 프라를 구축하기 어렵고 강수량에 따라 전력 공급량이 불 안정하며 송전 및 배전망의 낙후와 보수 불량에 의해 전력 손실률이 높은 상황이다(International Trade Administration, 2021). 이와 같은 상황에서도 전력 수요량은 매년 높아지고 있어 국가 차원에서는 다양한 개발협력 주체와 전력 보급 망을 설치하는 프로젝트들을 진행 중이다. 이에 탄자니아 정 부는 공공에너지 개발을 통해 미니 그리드 또는 오프 그리 드와 같은 형태의 분산형 전력 공급망을 저비용으로 구축 하고자 노력하고 있다(Tanzania Electric Supply Company Limited, 2015).

한편, 교통 인프라의 개선은 탄자니아 정부의 개발 전략 중에서 높은 우선순위를 점유하고 있다. 탄자니아 정부는 1997년 TANROADS(The Tanzania National Roads Agency)
을 설립하여 도로 포장과 운영 효율성을 도모하고 있으나, 2018 년 기준, 전체 주 도로 중 약 $67 \%$ 인 $8,211 \mathrm{~km}$ 가 포장 된 반면, 지방 도로는 $6.4 \%$ 인 $1,508 \mathrm{~km}$ 만이 포장되어 있 어 지방 도로에서의 교통 인프라가 상당히 취약한 상태로 (International Trade Administration, 2021), 월드 뱅크(The World Bank) 등 다양한 국제기구에서 탄자니아의 교통 인 프라 구축 및 유지를 위해 지원하고 있다(United Nations Road Safety Collaboration group, 2020).

한편, 르완다, 케냐, 우간다와 같은 동아프리카에서는 정 부 및 민간기업을 중심으로 전기 모빌리티에 대한 연구와 인프라를 구축하고 있는데, 르완다는 아프리카에서 전기 모 빌리티를 최초로 도입한 국가로써 스마트 시티와 지능형 교 통 수단을 구축하고자 노력하고 있다. 케냐에서는 많은 스 타트업들이 충전소 설치 및 배터리 대여 서비스를 통해 전 기 모빌리티의 영역을 확대해 나가고 있으며, 우간다에서는 전기 버스, 전기 자동차 등을 제작하는 공장을 건설하고 있 다. 탄자니아 정부는 UN SDGs의 이행 수단으로 전기 모빌 리티로의 전환을 제시하였는데, 이를 위해 탄자니아 국립 교 통 연구소(NIT), 국립 교통 연구 센터, 다르 에스 살람 대학 전기 공학부 등이 참여하여 전기 모빌리티 인증에 대한 차 량 표준을 제정하고 시험 방법을 도출하고 있다.

\section{2. 전기 모빌리티 요구 기능}

전기 자동차는 내연기관 자동차에 비하여 저비용으로 운 용유지가 가능한 것으로 알려져 있는데, 전기 오토바이의 경 우, 내연기관 오토바이에 비하여 약 30 분의 1 수준의 비용 으로 운용할 수 있다(Kim and Shin, 2014). 그러나 저소득 국가인 탄자니아에서는 충전소의 부족으로 충분한 양의 전 기 에너지를 공급하기 어려울 수 있으며 인프라 개발에 대 한 투자 또한 원활하지 못한 상태이다.

이러한 제한사항은 전기 모빌리티의 스마트화를 통한 에 너지 사용 모니터링 및 최적화를 통해 에너지 수요와 공급 의 균형을 맞춤으로써 극복할 수 있을 것이다. 이를 위해 실 시간 데이터 수집과 통신을 가능하게 하는 IoT(Internet of Things) 기술의 적용이 필요하다. 아두이노와 같은 저가의 마이크로 컨트롤러를 이용하고 $2 \mathrm{G}$ 데이터 통신모듈을 사용 한다면 탄자니아의 환경에서도 사용자와 관리자의 무선 데 이터 통신을 효과적으로 가능하게 할 수 있다. 또한 배터리 모니터링을 위한 전류센서와 전압센서, 위치 모니터링을 위 한 GPS, 도로의 상태를 모니터링 할 수 있는 가속도 센서 등을 적용하여 전기 모빌리티를 스마트화한다면 부족한 충 전 인프라와 개발이 요구되는 현지 도로상태에도 전력운영 최적화와 전기 모빌리티 상태 모니터링을 통해서 효율적인 전기 모빌리티의 운영이 가능할 것이다. 

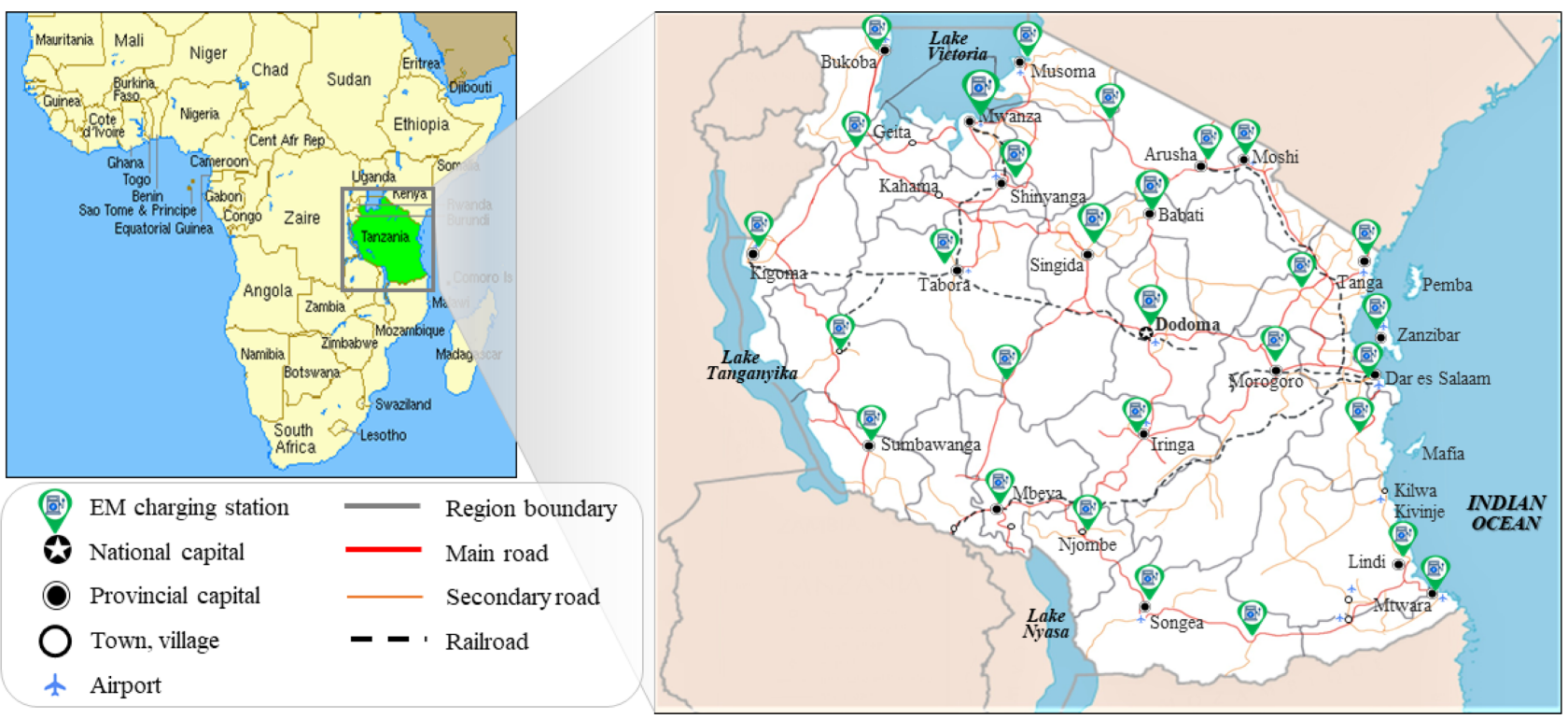

Figure 1. Concept map of nodes for smart electric charging in Tanzania

\section{3. 충전 인프라 요구 기능}

지역이 넓으나 전력 공급 인프라가 미흡한 탄자니아와 같 은 국가 또는 지역에서는 독립 분산형 전력 공급 인프라가 전기 모빌리티를 충전하는 중요한 역할을 할 수 있을 것이 다. 하지만 전력 생산능력이 제한적인 분산형 전력 공급망 의 특성상 다수 지역에 대한 분산이 요구되며, 차량이 통행 하는 주도로 뿐만 아니라 비포장 외곽지역에서도 충전시스 템을 운용할 수 있는 방안이 고려되어야 한다.

현재 탄자니아는 최대도시인 다르 에스 살람을 제외하고 는 전기 모빌리티의 충전 인프라가 전무한 상태인데, Urban Electric Mobility Initiative(2020)에 따르면, 탄자니아에서의 전기 모빌리티는 비용 측면과 인프라 구축을 고려하여 2025 년 이후부터 본격적인 개발이 전망된다.

충전 인프라는 전기 모빌리티의 운용을 위한 필수 기반 요소로서, 전기 모빌리티 운용 지역 내 충전 인프라의 소요 판단은 충전소의 위치, 요구되는 전력 에너지의 양, 충전 시 간 등에 기반하여 판단이 가능하다.

Figure 1은 탄자니아의 전기 모빌리티의 운용에 필요한 충 전 인프라 구축 및 운영에 대한 개념도로, 실제 전기 모빌 리티가 운영되면 데이터의 수집과 분석을 통해 보다 정확 한 충전 인프라 소요를 판단할 수 있을 것이다.

\section{탄자니아 전기 모빌리티 시스템 개발에 대한 제언}

\section{1. 스마트 전기 모빌리티 운영 시스템}

본 연구에서는 앞서 논의된 전기 모빌리티 운영 요구사 항과 탄자니아 현지 상황을 고려하여 탄자니아에서 운용 가 능한 스마트 전기 모빌리티 운영 시스템, SEMOS(Smart Electric Mobility Operating System)를 제안하고자 한다. SEMOS는 전기 모빌리티에 다양한 센서와 통신모듈을 적 용하여 스마트화 하는 한편, 탄자니아에 기 설립된 독립형 태양광 발전소에 전기 모빌리티를 연동시킴으로써, 충전 스 케쥴을 최적화 할 수 있도록 한다.

기존에 아프리카 농촌 지역의 전기차 충전소 최적화에 대 한 연구가 일부 수행되었으나(Bokopane et al., 2014; Bimenyimana et al., 2021; Ekren et al., 2021), 대부분 시스 템에 대한 많은 가정과 단순화된 데이터가 적용된 시뮬레 이션에 기반하고 있다. 한편, 오토바이는 가나, 케냐, 탄자 니아, 우간다 등 아프리카 주요 국가의 중심 교통수단으로, 비 포장도로에서의 유용한 활용성으로 아프리카 국가에서 널 리 활용되고 있는데(Bishop et al., 2018), 본 연구에서는 다 양한 전기 모빌리티 중 전기 오토바이를 대상으로 한 충전 운영 시스템을 제안한다. Figure 2는 본 논문에서 제안하고 자 하는 시스템의 개념도로, 1) 스마트 모니터링 시스템, 2) 독립형 태양광 발전소 통신 및 모니터링 시스템, 3) 충전 스 케쥴 및 경로 최적화 시스템으로 구성된다.

\section{1 스마트 모니터링 시스템}

전기 모빌리티의 상태를 모니터링 하기 위해서는 배터리 의 특성인 배터리 잔존용량(State of Charge), 배터리 상태 (State of Health)를 포함하여 오토바이 위치, 속도, 고도 및 


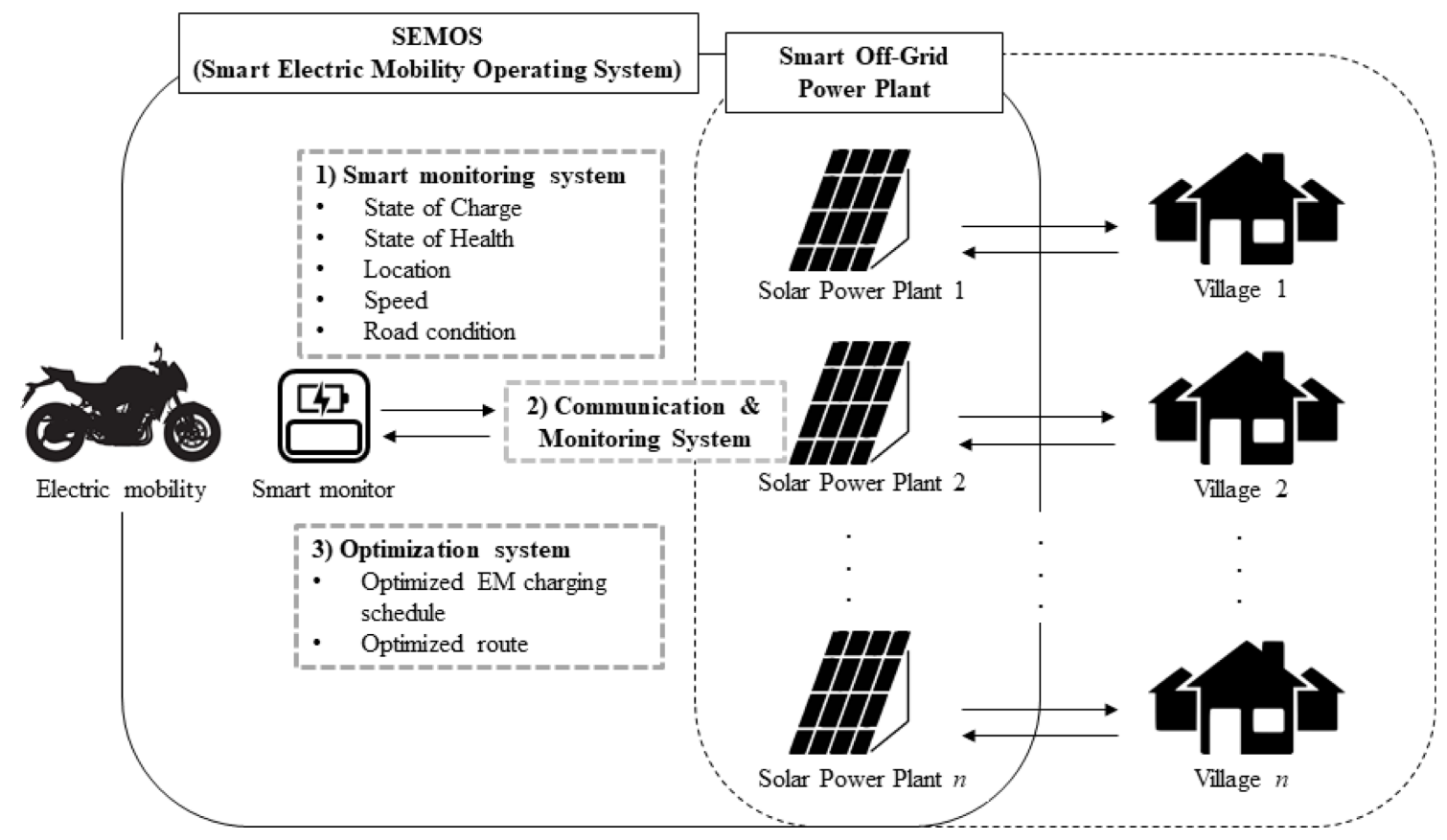

Figure 2. Concept diagram of SEMOS

도로 상태와 같은 변수들을 모니터링하여야 한다. 배터리의 잔존용량과 건강상태는 배터리 방전과 수명을 측정하기 위 한 중요한 요인으로 전류 센서를 이용하여 측정 및 산출이 가능하다(Chang, 2013). 오토바이의 위치, 속도 및 고도 또 한 배터리의 지속성에 영향을 줄 수 있는 요인이며 충전 스 케쥴링을 위해서 반드시 고려되어야 할 변수들로, GPS 모 듈을 통해 데이터 수집이 가능하다.

전기 오토바이의 상태를 모니터링하기 위한 컴퓨팅 시스 템은 데이터의 크기를 최소화하고 에지(edge) 수준에서 빠 르게 처리할 수 있도록 아두이노 기반의 시스템으로 구축 할 수 있다. 개발도상국의 운영환경을 고려하여 전체 시스 템 비용을 낮추기 위한 방안이 필요한데, 아두이노는 전기 오토바이의 모니터링을 위한 상태정보의 수집 및 처리에 충 분한 컴퓨팅 장치로 활용될 수 있다.

\section{2 독립형 태양광 발전소 통신 및 모니터링 시스템}

오토바이 운전자와 태양광 발전소 간의 실시간 통신은 기 존 태양광 인프라와 호환할 수 있도록 설정한다. 통신 인프 라가 거의 구축되어 있지 않은 개발도상국에서의 안정적 통 신 시스템 운영을 위해 SEMOS는 GSM(Global System for Mobile communication, 모바일 $2 \mathrm{G}$ 개인휴대통신) 통신을 사 용한다. 탄자니아 농촌 지역의 경우 와이파이 기반 데이터 통신이 거의 불가한 반면, 현지에서는 GSM 통신이 보다 안 정적으로 활용될 수 있다. 태양광 발전소의 위치 및 가용 전 력 데이터는 통신을 통해 전기 오토바이 운용자에게 전송
되고, 전송된 데이터를 통해 운용자는 발전소의 가용 상태 를 인지할 수 있게 된다.

\section{3 충전 스케쥴 및 경로 최적화}

충전 인프라가 충분히 갖춰지지 않은 지역에서 전기 오 토바이를 운영하기 위해서는 충전 스케쥴과 경로에 대한 예 측 및 최적화가 반드시 필요하다. 배터리의 잔량을 측정하 고 인접 충전소까지의 거리를 계산하여 현재의 배터리 수 준으로 목적지 까지의 도착 가능성을 예측하는 한편, 배터 리 소모의 최소화 및 최적의 이동 경로를 데이터를 기반으 로 판단한다. 이러한 최적화의 과정은 스마트 모니터링 시 스템에서 수집된 데이터들의 총체적 분석을 통해 가능한데, 이를 통해 운영환경이 열악한 지역에서의 전기 모빌리티 운 영 가능성을 확보할 수 있다.

\section{2. 스마트 전기 모빌리티 운영 시스템 적용 시나리오 및 시 범운행}

본 연구에서 제안하고자 하는 스마트 전기 모빌리티 운 영 시스템을 탄자니아 아루샤(Arusha) 지역에 설립된 태양 광 발전소를 기반으로 적용 시나리오를 구상하였다. 탄자니 아의 응구르도토(Ngurdoto)와 음칼라마(Mkalama)에는 서울 대학교와 탄자니아에서 활동하는 iTEC(Innovative Technology and Energy Center)가 설립한 세 개의 태양광 발전소가 운영되고 있다(Figure 3). Table 1은 세 개의 독립형 태양광 발전소의 사양으로, 현재 150 가구 이상에 전기를 공급하고 
Table 1. Specifications of three solar off-grid plants in Tanzania

\begin{tabular}{|c|c|c|c|c|c|c|}
\hline Name & Village & $\begin{array}{c}\text { Position } \\
\text { (latitude/longitude) }\end{array}$ & Power output & Battery & Output voltage & Payment \\
\hline Mkalama (2018) & Mkalama & $-3.527 / 37.420$ & $10 \mathrm{~kW}$ & $200 \mathrm{Ah} \times 32 \mathrm{EA}$ & \multirow{2}{*}{220 VAC } \\
Friendship (2019) & Ngurdoto & $-3.328 / 36.906$ & $7 \mathrm{~kW}$ & $375 \mathrm{Ah} \times 16 \mathrm{EA}$ & Pre-payment system \\
\cline { 1 - 4 } Hope (2019) & Ngurdoto & $-3.324 / 36.909$ & $7 \mathrm{~kW}$ & $220 \mathrm{Ah} \times 16 \mathrm{EA}$ & & \\
\hline
\end{tabular}

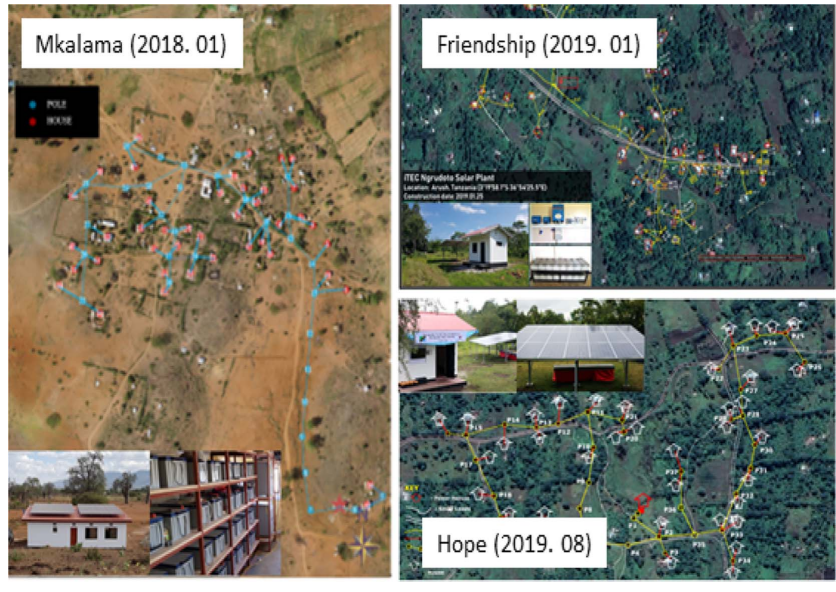

Figure 3. Off-grid solar plants in three villages

있다.

아프리카를 비롯한 개발도상국가에서는 많은 오토바이가 택시로 사용되고 있다. 전기오토바이의 경우 저렴한 운영, 정비비용과 더불어 충전비용은 개솔린 연료비용의 $25 \%$ 정 도의 비용이 예상되어 경제적이지만, 오토바이 운영자의 집 에서 전기오토바이를 충전할 수 있는 안정적인 전기 인프 라가 부족하기 때문에 대부분의 오토바이 배터리 충전은 충 전소에서 하게 될 것으로 예상된다. 이 경우 오랜 시간이 걸 리는 충전시간이 중요한 장애요소가 된다. 이런 경우를 고 려하여 충전소에서 전기 오토바이 배터리의 즉석 교환서비
스를 추가하면 충전시간 문제를 해소할 수 있고 운행중 방 전시의 어려움도 해결할 수 있다. 방전되어 교환된 배터리 들은 모아서 교외의 태양광 발전소에서 충전후 각 충전소 에 다시 배달하는 시스템을 구축하면 보다 효율적이고 지 속가능한 시스템으로 운영 가능할 것이다.

Figure 4는 설립된 3개의 독립형 태양광 발전소를 충전 인 프라로 판단하고 전기 오토바이 기반의 스마트 전기 모빌 리티 운영 시스템의 적용 가능성을 도시한 것이다. 먼저, SEMOS는 세 태양광 발전소의 전력 용량, 전기 오토바이의 최대 주행 가능 시간, 기타 정보 및 제한 요소를 고려하여 주행을 예측하고 최적화된 충전 스케쥴을 판단한다. 예를 들 어, 현재 전기 오토바이의 최대 주행거리가 $100 \mathrm{~km}$ 로 확인 되는 경우, 아루샤시에서 음칼라마 마을까지는 이동이 불가 능 할 수 있다. 이 경우, 최적의 경로는 응구르도토 마을로 이동하여 중간 충전을 한 후 다시 음칼라마 마을로 이동을 하는 방안이라고 할 수 있다. 하지만, 전기 오토바이의 현 재 상태를 모르고 있거나, 또는 응구르도토 마을 태양광 발 전소에 이상이 있는데 이를 인지하고 있지 못한다면 여러 변수로 인하여 목표지역까지 정상적으로 이동할 수 없을 것 이다. 부가하여, 도로의 상태(포장, 비포장, 오르막 및 내리 막길) 등과 같은 수시로 변화하는 주행 영향요인에 대한 실 시간 모니터링이 불가하다면 잔여 주행가능거리에 대한 예 측과 경로의 최적화는 큰 오차가 발생할 수 있다.

본 연구에서 제안된 시나리오의 가능성 검증을 위해 해

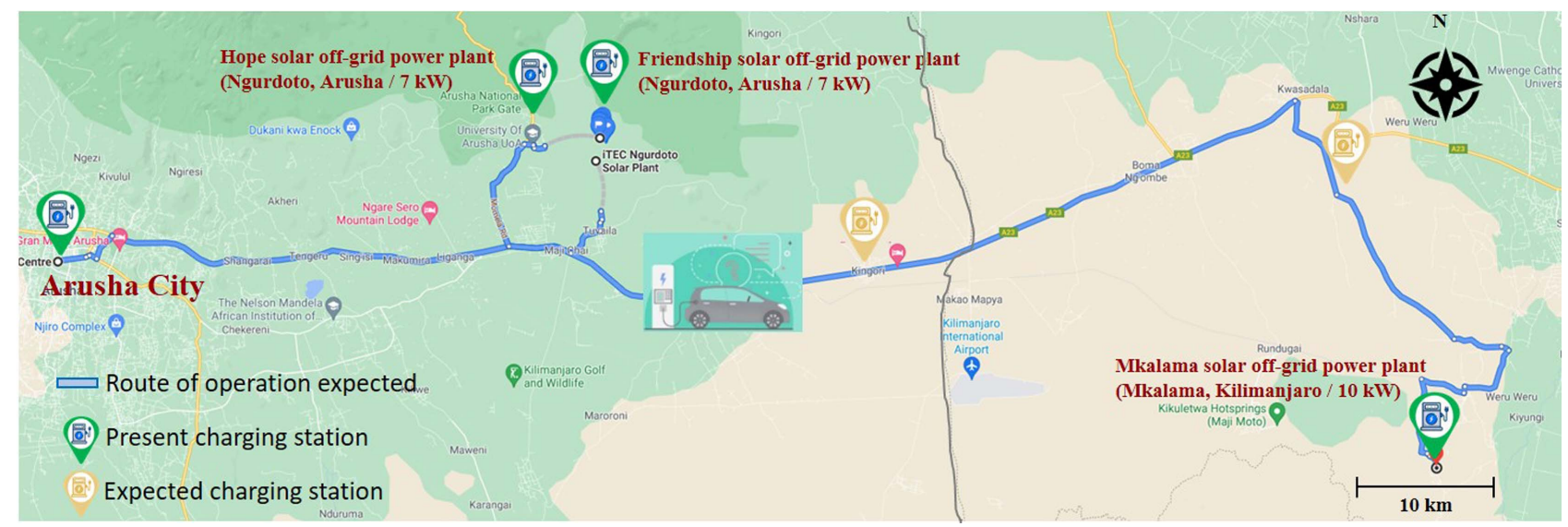

Figure 4. Application scenario of SEMOS (Map data @2019 Google) 
Table 2. Important criteria for SEMOS in Tanzania

\begin{tabular}{|c|c|c|c|c|}
\cline { 2 - 4 } \multicolumn{1}{c|}{} & $\begin{array}{c}\text { Environmentally } \\
\text { friendly }\end{array}$ & $\begin{array}{c}\text { Economically } \\
\text { sustainable }\end{array}$ & Easily operable & $\begin{array}{c}\text { Existing infrastructure } \\
\text { compatibility }\end{array}$ \\
\hline Smart monitoring & & & $\checkmark$ & $\checkmark$ \\
\hline 2G Communication & & & $\checkmark$ & $\checkmark$ \\
\hline Charging schedule optimization & $\checkmark$ & $\checkmark$ & & $\checkmark$ \\
\hline Optimized route recommendation & & $\checkmark$ & & $\checkmark$ \\
\hline Localized strategy for solar grid integration & $\checkmark$ & $\checkmark$ & & \\
\hline
\end{tabular}

당 지역에서 상용 전기 자동차를 이용하여 시범운행을 수 행하였다. 센서 기반의 다양한 데이터에 대한 모니터링을 수 행하지는 못하였지만, 3 개 태양광 발전소를 이동하며 운행 거리를 측정한 결과, 태양광 발전소와 통합된 스마트 전기 모빌리티 운영 시스템은 아프리카와 같은 개발도상국가에 서 충분히 효과적으로 운영 가능한 시스템으로 발전시킬 수 있음을 확인하였다(Frank and Ahn, 2021).

데이터 기반의 전기 모빌리티 운영 시스템은 운영과정에 서 축적된 다양한 도로 및 주행데이터를 기반으로 보다 정 확한 예측 및 최적화가 가능할 것이다. 또한, 가장 적절한 신규 충전소의 위치까지 도출할 수 있을 것이다.

\section{3. 탄자니아의 스마트 전기 모빌리티 운영 시스템 구축시 고 려사항}

모든 시스템은 운영되는 환경과 조건에 따라 특화된 요 소들을 고려하여 개발되어야 한다. 본 연구에서 제안하고자 하는 스마트 전기 모빌리티 운영 시스템은 탄자니아와 같 은 전기 보급률과 도로 포장률이 낮고 통신 사양의 제한이 있는 개발도상국 환경과 조건을 고려하여야 한다. Table 2 는 탄자니아에 전기 모빌리티 운영 시스템을 적용할 때 고 려하여야 할 사항을 정리한 것이다. 스마트 모니터링 기술 과 통신기술은 운용하기 쉽고 현지의 인프라와 호환이 가 능하여야 한다. 하드웨어적인 측면에서는 개발도상국의 상 황을 고려하여, 라즈베리파이 수준의 저가형 컴퓨팅 장치를 적용하여 소량의 데이터를 빠르게 처리하는 방안이 유용할 것이며, 통신 또한 넓은 지역에 통신 인프라가 구축되지 않 은 상황을 감안하여 $2 \mathrm{G}$ 및 로라(LoRa: Long Range)통신 등 현지에서 운용 가능한 방식을 채택할 필요가 있다.

한편, 충전 스케쥴 최적화는 환경친화적이면서도 경제적 으로 지속 가능하여야 하며, 경로 최적화는 경제적이면서도 다른 충전 인프라와 호환이 용이하여야 한다. 경로 최적화 와 관련해서는 모든 경로를 경유하는 최적 경로를 찾는 전 통적인 세일즈맨 문제로부터 최근 내비게이션과 같이 지도 상에서 가장 짧은 경로를 탐색하는 방법 등이 다양하게 연 구되고 있다. 접근 방법 또한 휴리스틱 방법, 유전 알고리
즘 등을 포함한 다양한 알고리즘들이 제시되고 있는데, 본 제안에서의 경로 최적화는 단순한 최단 거리의 도출보다 배 터리의 잔량과 충전소의 위치를 제약조건으로 하는 보다 복 잡한 문제로 고려되어야 할 것이다.

부가하여, 태양광 발전소는 현지의 여건에 맞게 환경친화 및 경제적 지속 가능성을 고려하여 구축하여야 한다. 전기 모빌리티 운영 시스템은 큰 비용이 소요되는 설비 인프라 구축과 첨단 기술이 적용된 운영 장비 개발이 동시에 수행 되어야 하는 복합적 기술개발 사업이라고 할 수 있다. 이러 한 경우일수록 사전 숙고를 통해 지속가능한 시스템으로의 설계가 반드시 필요할 것이다. 비록, 아직 탄자니아 정부 차 원에서 태양광 발전소와 통합된 전기 모빌리티 운영 시스 템에 대한 상용화 계획은 없으나, 아프리카 지역에서의 전 기 자동차 및 오토바이에 대한 수요가 지속 증가하고 있고, 신재생에너지의 중요성이 대두되고 있는 글로벌 상황을 탄 자니아 현지의 전력 상황과 함께 고려한다면, 본 제안의 시 스템은 상업화를 통해 국가 교통 인프라 구축에 유용한 방 법으로 활용될 수 있을 것이다.

\section{결론}

본 연구에서는 탄자니아에 설립된 독립형 태양광 발전소 를 충전 인프라로 하는 스마트 전기 모빌리티 운영 시스템 의 적용 가능성을 제안하고 기존의 상용 전기 모빌리티를 이용한 시범운행을 통해 가능성을 검증하였다. 스마트 전기 모빌리티 운영 시스템은 아두이노와 센서를 이용하여 전기 모빌리티의 상태를 실시간으로 모니터링 하는 한편, 주변 태 양광 발전소와의 통신을 통해 발전소의 전력데이터를 수집 한다. 수집된 데이터는 전기 모빌리티 데이터와 통합적으로 분석되어 전기 모빌리티의 주행 가능거리를 예측하고, 목적 지까지의 최적 경로와 충전 스케쥴을 제안한다. 탄자니아 지 역에서 운영될 전기 모빌리티 시스템은 현지의 환경과 특 성을 고려하여 친환경성, 경제적 수용가능성, 운용 용이성, 기존 시스템과의 호환가능성 등의 요소를 반영하여 설계하 여야 한다. 이를 통해 글로벌 환경 문제에 강건하게 대응할 
수 있을 뿐만 아니라 실제 지속가능하게 운영할 수 있을 것 이다.

본 논문에서 제시한 탄자니아 지역의 스마트 전기 모빌 리티 운영 시스템 시나리오는 실제 실험을 통하여 구현 가 능성을 검증할 예정이다. 이를 통해 태양광 발전소 인프라 의 효율적 활용과 함께 친환경적 모빌리티 운영시스템의 구 축 가능성을 명확히 확인할 수 있을 것이다.

태양광 발전소는 전 세계적 문제로 심화되고 있는 지구 온난화에 대응할 수 있는 중요한 대안이 될 수 있다. 이를 이용한 전기 모빌리티 시스템은 신재생 에너지를 확산하고 탄소 배출을 획기적으로 저감할 수 있는 의미있는 접근이 라고 할 수 있다. SDGs는 인류의 지속가능성을 보장할 수 있는 공공의 목표를 지향한다. 본 논문에서 제안한 스마트 전기 모빌리티 운영 시스템은 이러한 SDGs의 관점에서 인 류의 지속가능성을 위해 반드시 필요한 시스템이라고 할 수 있을 것이다.

\section{Acknowledgements}

이 논문은 교육부의 재원으로 한국연구재단의 지원을 받 아 수행된 국제협력 선도대학 육성-지원 사업(과제번호: 2020H1A7A2A02000043)의 연구 결과이며, 국제 협력 프로 그램을 수행할 수 있도록 지원해 준 SNU 10-10 프로젝트 에 감사를 표합니다.

\section{References}

Ahmadian, A., Sedghi, M., Elkamel, A., Fowler, M., and Golkar, M. A. (2018). Plug-in electric vehicle batteries degradation modeling for smart grid studies: Review, assessment and conceptual framework, Renewable and Sustainable Energy Reviews, 81, pp. 2609-2624.

Bimenyimana, S., Wang, C., Nduwamungu, A., Asemota, G. N. O., Utetiwabo, W., Ho, C., Niyonteze, J. D. D., Hagumimana, N., Habineza, T., Bashir W., Mesa, C. K., and Mo, Y. (2021). Integration of Microgrids and Electric Vehicle Technologies in the National Grid as the Key Enabler to the Sustainable Development for Rwanda. International Journal of Photoenergy, pp. $1-12$.

Bishop, T., Barber, C., Mwaipopo, H., Rettie, N., KrasnoluckaHickman, A., Divall, D., and Porter, G. (2018). Enhancing understanding on safe motorcycle and three-wheeler use for rural transport, Inception Report, Amend and Transaid, http:/ /www.research4cap.org (accessed Sept, 2021).

Bokopane, L., Kusakana, K., and Vermaak, H. J. (2014). Hybrid
System Configurations and Charging Strategies for Isolated Electric Tuk-Tuk Charging Station in South Africa, Journal of Electrical, Robotics, Electronics and Communications Engineering, 8(11), 1395-1400.

Chang, W.-Y. (2013). The State of Charge Estimating Methods for Battery: A Review, ISRN Applied Mathematics, 2013(1), pp. 1-7.

Chokkalingam, B., Padmanaban, S., Siano, P., Krishnamoorthy, R., and Selvaraj, R. (2017). Real-time forecasting of EV charging station scheduling for smart energy systems, Energies, 10(3), pp. 377.

CO2 Emissions from Transport (\% of Total Fuel Combustion) Tanzania, The World Bank, https://data.worldbank.org/indicator/EN.CO2.TRAN.ZS?end=2014\&amp;locations $=$ TZ\&amp;start=2014\&amp;view $=$ bar $\quad$ (accessed Sept, 2021).

Ekren, O., Canbaz, C. H., and Güvel, Ç. B. (2021). Sizing of a solar-wind hybrid electric vehicle charging station by using HOMER software, Journal of Cleaner Production, 279, 123615. pp. 1-13.

Erick, A. O., and Folly, K. A. (2020). Power Flow Management in Multi-Source Electric Vehicle Charging Station, IFAC-PapersOnLine, 53(2), pp. 12590-12595.

Fathabadi, H. (2017). Novel solar powered electric vehicle charging station with the capability of vehicle-to-grid, Solar Energy, 142, pp. 136-143.

Frank, A. M., and Ahn, S. H. (2021). Energy systems Integration: Optimizing infrastructure of Africa's offgrid power plants to adapt Electric Vehicle smart charging, Proceedings of the International Conference on Energy, Aquatech and Sustainability 2021 (ICEAS 2021), Academic Society for Appropriate Technology, p.6.

Gandoman, F. H., Ahmadi, A., Van den Bossche, P., Van Mierlo, J., Omar, N., Nezhad, A. E., Mavalizadeh, H., and Mayet, C. (2019). Status and future perspectives of reliability assessment for electric vehicles, Reliability Engineering \& System Safety, 183 , pp. 1-16.

Garidzirai, R. (2020). Time Series Analysis of Carbon Dioxide Emission, Population, Carbon Tax and Energy use in South Africa, International Journal of Energy Economics and Policy, 10(5), 353.

Greenhouse Gases Equivalencies Calculator - Calculations and References. Environmental Protection Agency, https:// www.epa.gov/energy/greenhouse-gases-equivalencies-calculator-calculations-and-references (accessed Sept. 2021).

Hu, X., Jiang, J., Egardt, B., and Cao, D. (2015). Advanced power-source integration in hybrid electric vehicles: Multicri- 
teria optimization approach, IEEE Transactions on Industrial Electronics, 62(12), pp. 7847-7858.

International Trade Administration: Tanzania - Country Commercial Guide (Energy), https://www.trade.gov/country-commercial-guides/tanzania-energy (accessed Sept, 2021).

International Trade Administration: Tanzania - Country Commercial Guide (Transportation Infrastructure), https://www.trade.gov/ country-commercial-guides/tanzania-transportation-infrastructure (accessed Sept, 2021).

Khan, S., Ahmad, A., Ahmad, F., Shafaati Shemami, M., Saad Alam, M., and Khateeb, S. (2018). A comprehensive review on solar powered electric vehicle charging system, Smart Science, 6(1), pp. 54-79.

Kim, G., and $\mathrm{Sin}, \mathrm{O}$. (2014). 전기이륜차 기술동향, 전기의 세계, 16(11), pp. 32-40.

Mueller, O. M., and Mueller, E. K. (2014). Off-grid, low-cost, electrical sun-car system for developing countries, Proceeding of the IEEE Global Humanitarian Technology Conference, IEEE, California, October 19-23, pp. 14-17.

Nguyen, H., Zhang, C., and Mahmud, M. A. (2014). Smart charging and discharging of electric vehicles to support grid with high penetration of renewable energy, IFAC Proceedings Volumes, 47(3), pp. 8604-8609.

Rajper, S. Z., and Albrecht, J. (2020). Prospects of electric vehicles in the developing countries: a literature review, Sustainability, 12(5), pp. 1-19.

Renewables 2020 - Analysis - IEA. (2020). International Energy Agency, https://www.iea.org/reports/renewables-2020 (accessed Sept. 2021).

Schreyer, F., Luderer, G., Rodrigues, R., Pietzcker, R. C., Baumstark, L., Sugiyama, M., Brecha, R. J., and Ueckerdt, F. (2020). Common but differentiated leadership: strategies and challenges for carbon neutrality by 2050 across industrialized economies, Environmental Research Letters, 15(11), 114016.

Sun, C., Sun, F., Hu, X., Hedrick, J. K., and Moura, S. (2015, July). Integrating traffic velocity data into predictive energy management of plug-in hybrid electric vehicles, Proceeding of the 2015 American Control Conference, IEEE, Illinois, July 13, pp. 3267-3272.

Tanzania Electric Supply Company Limited. (2015). Annual report: for the 18 -month period ended $30^{\text {th }}$ June 2015 , pp. 112.

The united republic of Tanzania. Ministry of energy and minerals. (2015). Electricity Supply Industry Reform Roadmap, pp. 1115.

The united republic of Tanzania. planning commission. (1999). The Tanzania development vision 2025, pp. 3-7.

Thellufsen, J. Z., Lund, H., Sorknæs, P., Østergaard, P. A., Chang, M., Drysdale, D., Nielson, S., Djørup, S. R., and Sperling, K. (2020). Smart energy cities in a $100 \%$ renewable energy context, Renewable and Sustainable Energy Reviews, 129, 109922.q

United Nations Road Safety Collaboration group (UNRSC). (2020). The ten step plan for safer road infrastructure, www.gtkp.com (accessed Sept. 2021)

Urban Electric Mobility Initiative (UEMI), UEMI in Tanzania, http://www.uemi.net/dar-es-salaam---tanzania.html (accessed Sept, 2021).

World meteorological organization (2020). State of the Global Climate 2020: Provisional report, https://public.wmo.int/en/ our-mandate/climate/wmo-statement-state-of-global-climate (accessed Sept, 2021).

Yang, Z., Li, K., Foley, A., and Zhang, C. (2014). Optimal scheduling methods to integrate plug-in electric vehicles with the power system: a review, IFAC Proceedings Volumes, 47(3), pp. 8594-8603. 